\title{
Экология человека
}

๑ ПЕТРОВА М.М., ПРОНИНА Е.А., БАРОН И.И., ПОЗАНЯКОВА А.А., РОМАНОВА М.В., ЯГАНОВА С.С. УАK 378.172

\section{ОТНОШЕНИЕ СТУАЕНТОВ КРАСНОЯРСКОГО ГОСУААРСТВЕННОГО МЕАИЦИНСКОГО УНИВЕРСИТЕТА ИМЕНИ ПРОФЕССОРА В.Ф. ВОЙНО-ЯСЕНЕЦКОГО К ФИЗИЧЕСКОЙ АКТИВНОСТИ \\ М.М. Петрова, Е.А. Пронина, И.И. Барон, А.А. Позднякова, М.В. Романова, С.С. Яганова} ГБОУ ВПО Красноярский государственный медицинский университет имени профессора В.Ф. Войно-Ясенецкого, ректор - А.М.Н., проф. И.П. Артюхов;

кафедра поликлинической терапии, семейной медицины и ЗОЖ с курсом ПО, зав. - А.М.Н., проф. М.М. Петрова.

Цель исслеgования. Изучение отношения стуgентов меgицинского университета к физической активности.

Материалы и метоgы. Провеgено анкетирование 126 стуgентов 1 и 6 курса.

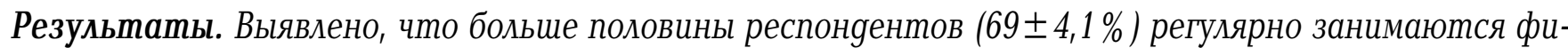
зическими упражнениями, с целью укрепить зgоровье $(25,4 \pm 43,9 \%)$, поggержать физическую форму $(23 \pm 3,7 \%)$, улучшить фигуру $(15,8 \pm 3,2 \%)$. Наибольшей популярностью среgи стуgентов пользуются фитнес, таниы (19,8 $23,6 \%)$, занятия в тренажерном зале $(14,3 \pm 3,1 \%)$, игровые вияы спорта $(10,3 \pm 42,3 \%)$, прогулки, хоэьба $(14,3 \pm 3,1 \%)$.

Закиючение. Больше половины студентов КрасГМУ регулярно занимаются физическими упражнениями. Ключевые слова: физическая активность, стуgенты.

\section{THE ATTITUDE OF THE STUDENTS OF KRASNOYARSK STATE MEDICAL UNIVERSITY NAMED AFTER PROFESSOR V.F. VOINO-YASENETSKY TO PHYSICAL ACTIVITY}

M.M. Petrova, E.A. Pronina, I.I. Baron, A.A. Pozdnyakova, M.V. Romanova, S.S. Yaganova Krasnoyarsk State Medical University named after prof. V.F. Voino-Yasenetsky

Aim of the research. To study medical university students' attitude to the physical activity. Materials and methods. It was conducted the questioning of 126 students from 1 and 6 courses.

Results. It was revealed that more than a half of respondents $(69 \pm 4,1 \%)$ regularly engage in physical exercises in order to improve their health $(25,4 \pm 43,9 \%)$, to support the physical shape $(23 \pm 3,7 \%)$, to improve the body $(15,8 \pm 3,2 \%)$. Most popular among students are fitness, dancing $(19,8 \pm 3,6 \%)$, training in the gym $(14,3 \pm 3,1 \%)$, playing sports $(10,3 \pm 42,3 \%)$, walking $(14,3 \pm 3,1 \%)$.

Conclusion. More than a half of the KrasGMU students are engaged in physical exercises regularly.

Key words: physical activity, students.

\section{Введение}

В условиях интенсификации учебного процесса, все возрастающих требований к качеству образования и уровню профессиональной подготовки специалистов актуальным является вопрос сохра- нения здоровья студентов. Физические упражнения положительно влияют на физическую и умственную работоспособность. Спортивные физические нагрузки играют важную роль в вопросах адаптации, формировании функциональ- 
ных резервов организма [1]. Занятия физической культурой являются обязательным элементом программы обучения студента университета. В тоже время, по данным некоторых авторов, дети, которые активно занимаются спортом в свободное от школы время, став взрослыми продолжают (спустя 20 лет) вести более активный образ жизни [3]. В долгосрочной перспективе регулярные физические упражнения снижают общий риск смерти и риск смерти от сердечно-сосудистых заболеваний на 30-35\% [2].

Целью нашего исследования явилось изучить отношение студентов КрасГМУ к физической активности, помимо занятий физкультурой в рамках университетской программы.

\section{Материалы и методы}

В задачи исследования входило: 1. Изучить частоту дополнительных занятий спортом студентов КрасГМУ в зависимости от факультета. 2. Выяснить причины, которые побуждают студентов к дополнительным занятиям спортом. 3. Узнать причины, которые мешают студентам дополнительно заниматься физическими упражнениями.

В соответствии с задачами исследования нами была разработана анкета. Было проведено анонимное анкетирование студентов лечебного, стоматологического, педиатрического и фармацевтического факультетов. В анкетировании приняли участие 126 человек, из них 21 студент педиатрического факультета, 29 студентов стоматологического, 25 - педиатрического, 51 студент лечебного факультетов, обучающихся на 1, 2 и 6 курсе. Была изучена литература по данной теме. Статистическая обработка данных проводилась с помощью программы Statistica 8.0. Описательная статистика результатов исследования представлена процентными долями и их стандартными ошибками $( \pm m)$.

\section{Результаты и обсуждение}

В ходе анкетирования у нас получились следующие результаты. 69 \% опрошенных студентов, Аополнительно, помимо занятий физкультурой в университете занимаются спортом (рис. 1).

Только $35,7 \pm 4,3 \%$ студентов занимаются от случая к случаю и $64,0 \pm 4,3 \%$ студентов занимаются регулярно от 1-2 раз в неделю и чаще (рис. 2).

Студенты отдают предпочтение занятиям в спортзале, бассейне $(42,1 \pm 4,4 \%)$ или в домашних условиях $(39,7 \pm 4,4 \%)$. В секциях занимаются только 7,1 2,3\% опрошенных (рис. 3 ).

Среди наиболее популярных видов спорта (рис. 4) можно назвать фитнес, танцы $(19,8 \pm 3,6 \%)$, занятия в тренажерном зале $(14,3 \pm 3,1 \%)$, а также ходьба и прогулки $(14,3 \pm 3,1 \%)$. Также довольно широко распространены игровые виды спорта $(10,3 \pm 2,7 \%)$, бег $(11,1 \pm 2,8 \%)$ и велосипедные прогулки $(8,7 \pm 2,8 \%)$.

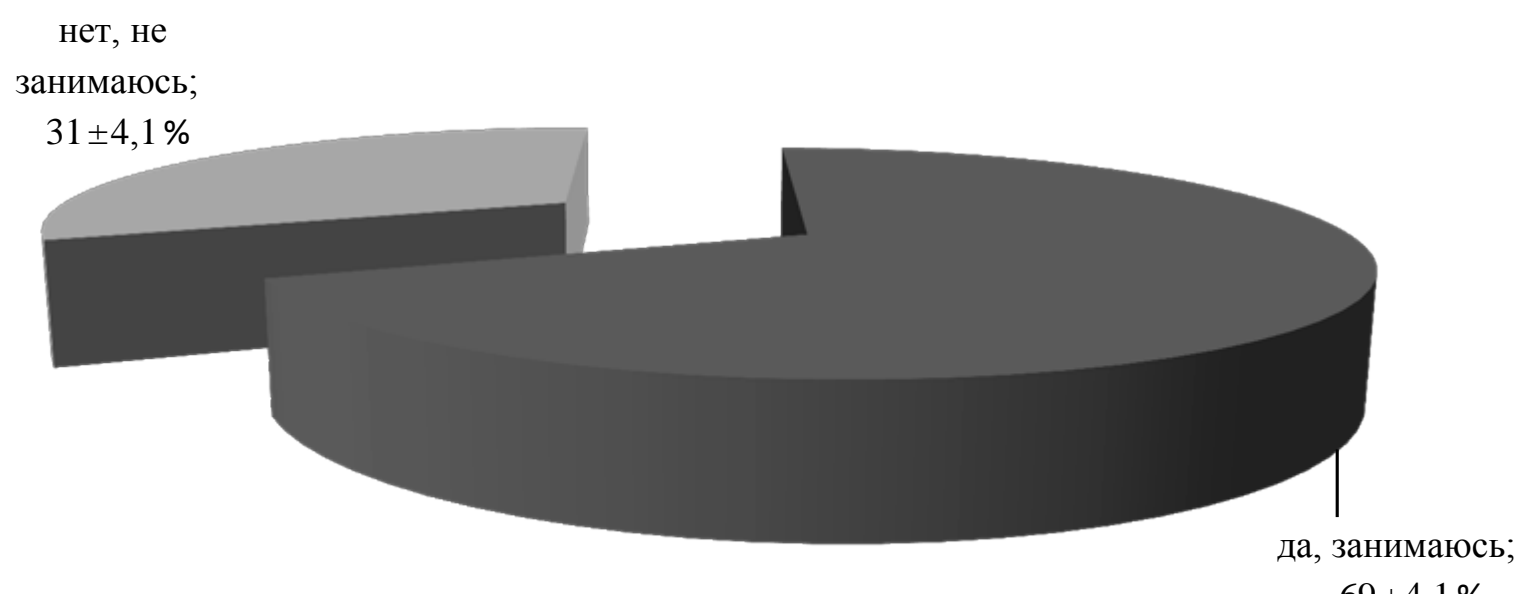

$69 \pm 4,1 \%$

Рuс. 1. Распространенность gополнительных занятий физическими упражнениями среgи стуgентов КрасГМУ. 


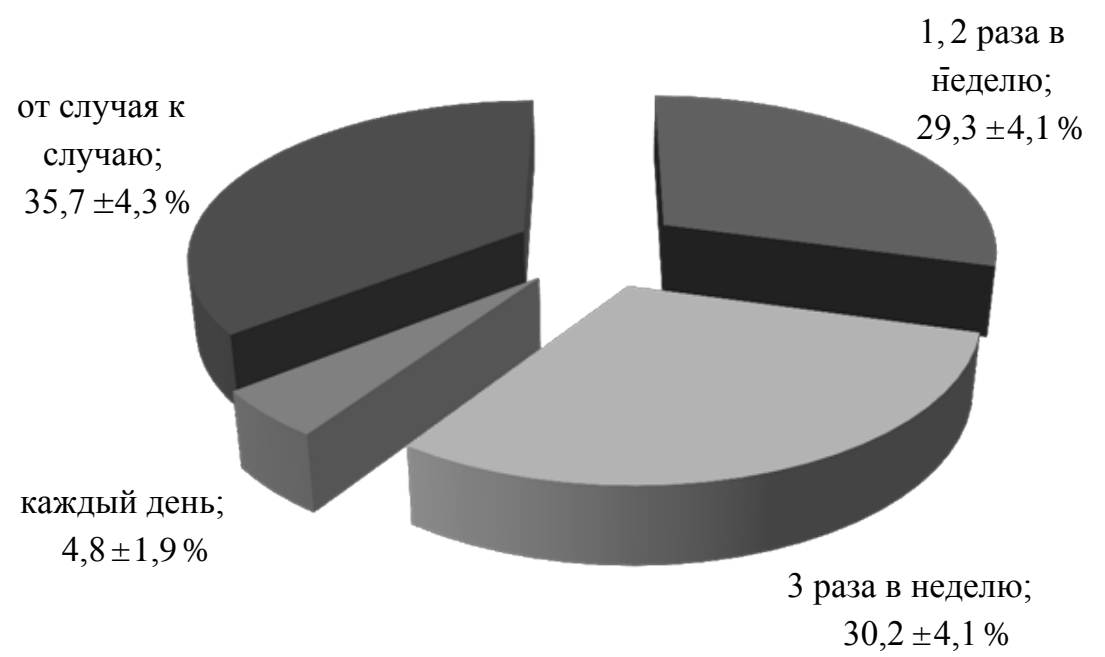

Рис. 2. Частота gополнительных занятий физическими упражнениями среgи стуgентов КрасГМУ.

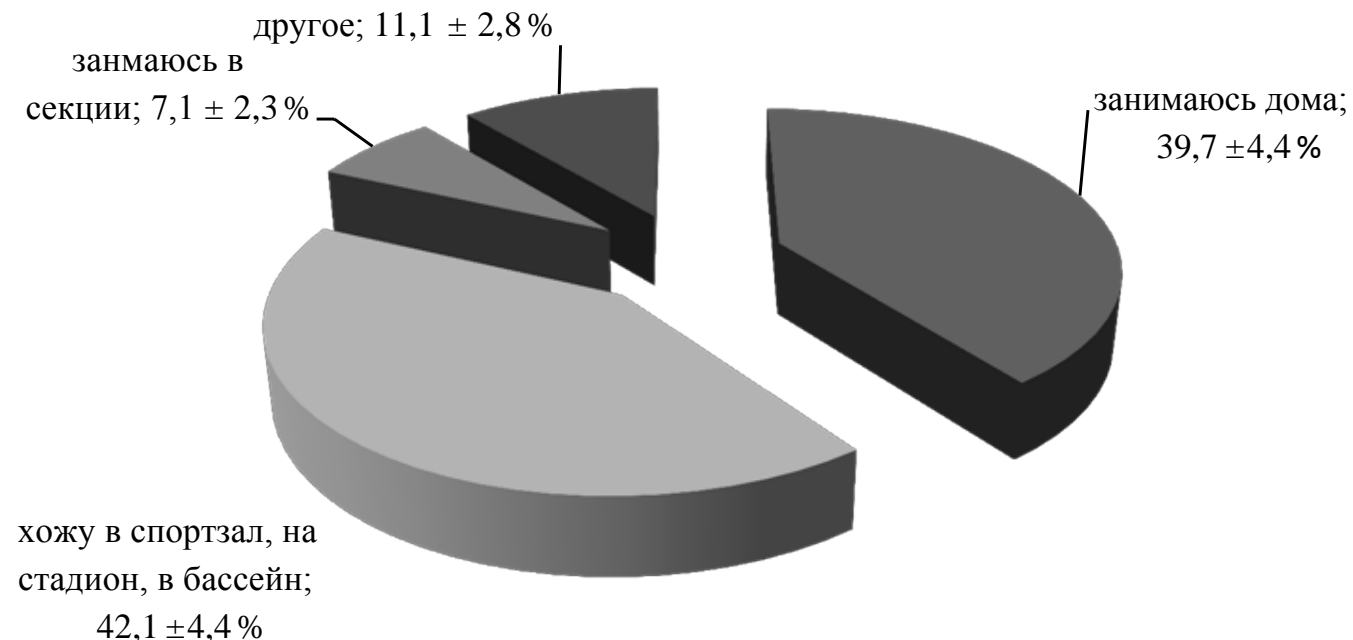

Рис. 3. Места ля занятий физическими упражнениями.

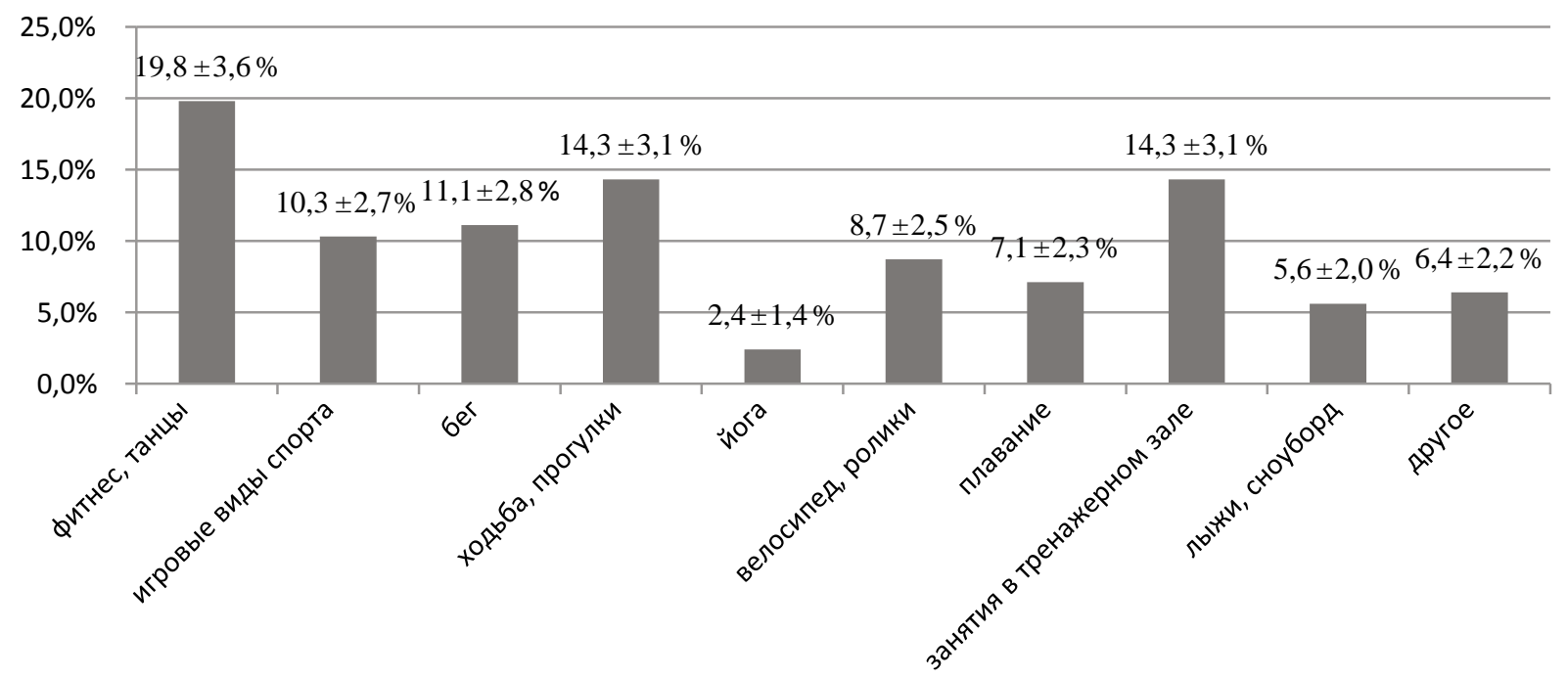

Puс. 4. Bugы gополнительных физических упражнений. 


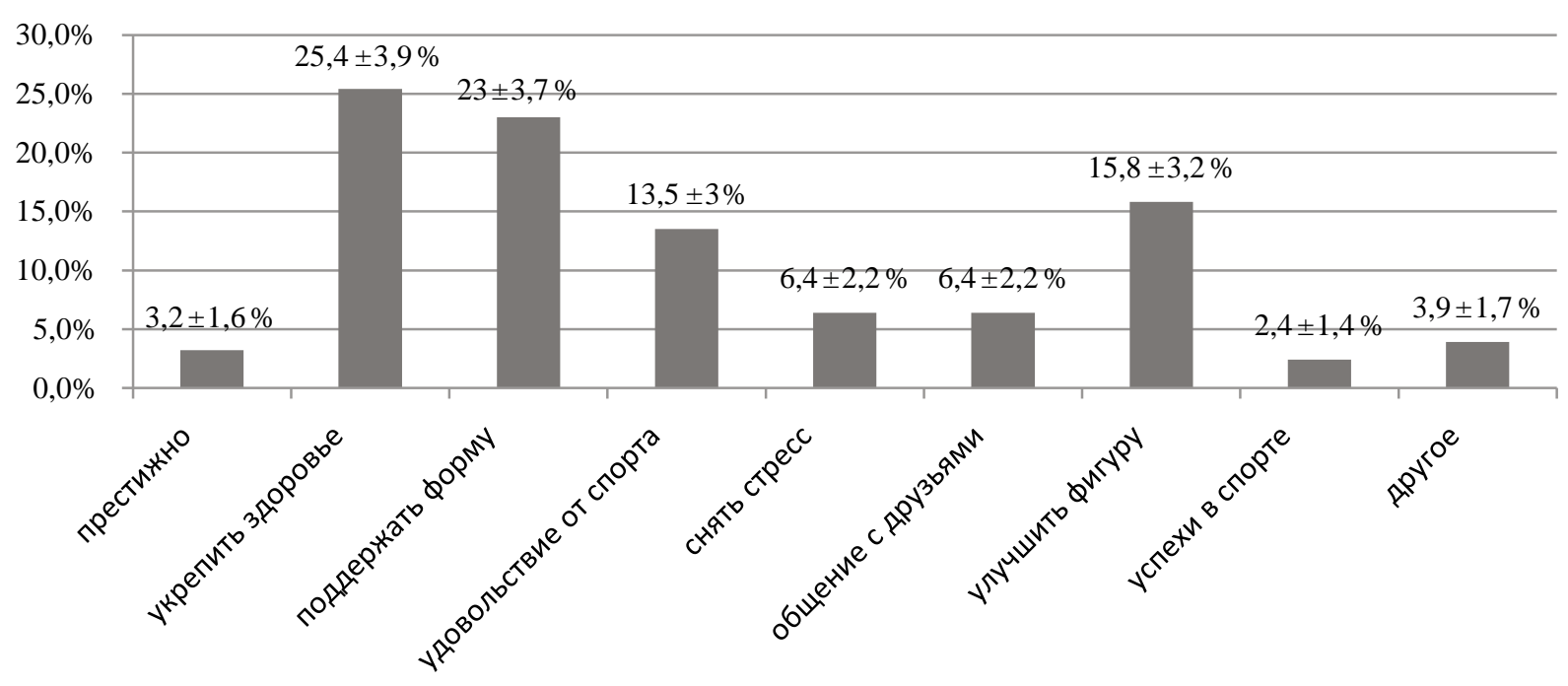

Рис. 5. Причины gополнительных занятий физическими упражнениями стуgентов КрасГМУ.

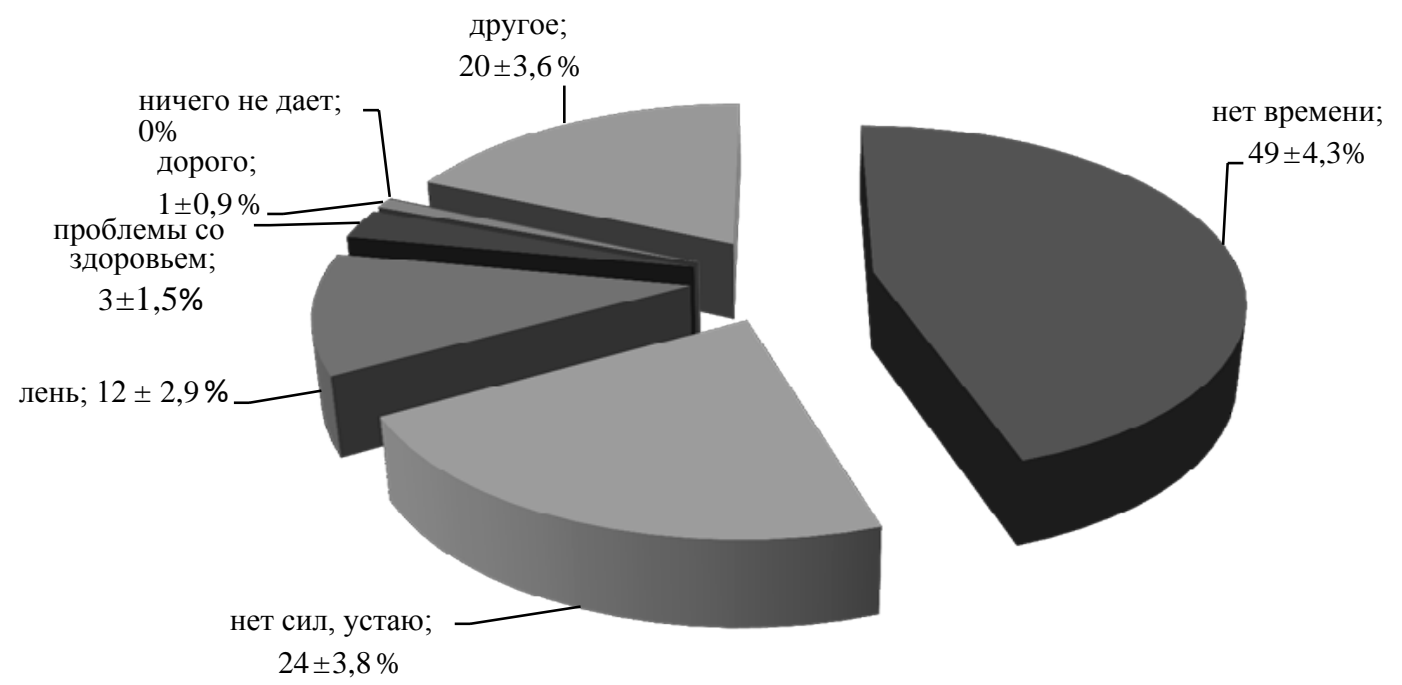

Рuс. 6. Причины, по которым стуgенты КрасГМУ отказываются от gополнительных занятий физическими упражнениями.

На наш взгляд интересными оказались причины, которые побуждают студентов дополнительно заниматься физическими упражнениями (рис. 5). На первое место вышли желание укрепить здоровье $(25,4 \pm 3,9 \%)$ и поддержать физическую форму $(23 \pm 3,7 \%)$. Не менее важными причинами оказались удовольствие от занятий спортом $(13,5 \pm 3,0 \%)$ и желание улучшить фигуру $(15,8 \pm 3,2 \%)$.

Среди причин, которые препятствуют дополнительным занятиям спортом в нашем вузе, на первом месте оказались отсутствие времени $(49 \pm 4,5 \%)$ и сил $(24 \pm 3,8 \%), 12 \pm 2,9 \%$ студентов сослались на лень (рис. 6).

\section{Заключение}

В заключение можно сказать, что больше половины студентов КрасГМУ занимаются спортом, помимо занятий физкультурой в университете. Причем $64 \pm 4,3 \%$ студентов занимается регулярно от 1-2 раз в неделю и чаще с целью улучшения здоровья и поддержания хорошей физической формы. Наиболее популярными видами спорта являются фитнесс, танцы, занятия в тренажерном зале, ходьба и прогулки.

\section{Литература}

1. Кальная Е.В., Шаханова А.В., Схакумидов Т.А., Меретукова А.Р. Влияние спортивных физических 
нагрузок на регуляторно-адаптивные возможности студенток с различной двигательной активностью // Вестник Адыгейского государственного университета. Серия 4: естественно-математические и технические науки. - 2014. - №3 (142). - С. 80-88.

2. Cleland V., Dwyer T., Venn A. Which domains of childhood physical activity predict physical activity in adulthood? A 20-year prospective tracking study // Br.J. Sports Med. - 2012. - Vol. 46, №8. - P.595-602.

3. Nocon M., Hiemann T., Müller-Riemenschneider F. at al Association of physical activity with all-cause and cardiovascular mortality: a systematic review and meta-analysis // Cardiovasc. Prev. Rehabil. - 2008. - Vol.15, №3. - P.239-246.

\section{References}

1. Kalnaya E.V., Shakhanova A.V., Skhakumidov T.A., Meretukova A.R. Influence of sports physical activities on regulatory and adaptive possibilities of girl-students with different physical activity // Bulletin of Adygeya State University. Series 4: naturalmathematical and technical sciences. - 2014. - №3 (142). - P. 80-88.

2. Cleland V., Dwyer T., Venn A. Which domains of childhood physical activity predict physical activity in adulthood? A 20-year prospective tracking study // Br.J. Sports Med. - 2012. - Vol. 46, №8. - P.595-602.

3. Nocon M., Hiemann T., Müller-Riemenschneider F. at al Association of physical activity with all-cause and cardiovascular mortality: a systematic review and meta-analysis / / Cardiovasc. Prev. Rehabil. - 2008. - Vol.15, №3. - P.239-246.

\section{Сведения об авторах}

Петрова Марина Михайловна - gоктор меgщцинских наук, профессор, завеgующая кафеgрой поликлинической терапии, семейной меgицины и ЗОЖ с курсом ПО, ГБОУ ВПО Красноярский госуяарственный меgицинский университет им. проф. В.Ф. Войно-Ясенецкого МЗ РФ.

Agрес: 660022, г. Красноярск, ул. Партизана Железняка, g. 1; mел.: 8 (391) 2280628; e-mail: stk99@yandex.ru.

Пронина Елена Александровна - канgugaт меgицинских наук, gоцент кафеgры поликлинической терапии, семейной меgицины и ЗОЖ с курсом ПО, ГБОУ ВПО Красноярский госуяарственный меgицинский университет им. проф. В.Ф. Войно-Ясенецкого МЗ РФ.

Agрес: 660022, г. Красноярск, ул. Партизана Железняка, g. 1; mел.: 8 (391) 2280628; e-mail: diinny@mail.ru.

Барон Ирина Иосифовна - канgugam меgицинских наук, gоцент кафеgры поликиинической терапии, семейной меgицины и
ЗОЖ с курсом ПО, ГБОУ ВПО Красноярский госуяарственный меgицинский университет им. проф. В.Ф. Войно-Ясенецкого МЗ РФ.

Agpec: 660022, г. Красноярск, ул. Партизана Железняка, g. 1; тел.: 8 (391) 2280628; e-mail: irinabaron@mail.ru.

Позднякова Александра Александровна - стуgентка 204 группы факультета фундаментального меgицинского образования специальность "Пеgиатрия», ГБОУ ВПО Красноярский госуяарственный меgицинский университет им. проф. В.Ф. Войно-Ясенецкого МЗ РФ.

Agрес: 660022, г. Красноярск, ул. Партизана Железняка, g. 1; тел.: 8 (391) 2280628; e-mail: alex.pozdnyackowa@yandex.ru.

Романова Мария Викторовна - стуgентка 204 группы факультета фундаментального меgицинского образования, специальность «Пеgиатрия», ГБОУ ВПО Красноярский государственный меgицинский университет им. проф. В.Ф. Войно-Ясенецкого МЗ РФ.

Agpec: 660022, г. Красноярск, ул. Партизана Железняка, g. 1; тел.: 8 (391) 2280628; e-mail:Romil_16@mail.ru.

Яганова Светлана Сергеевна - стуgентка 202 группы факультета фундаментального меgицинского образования специальность "Аечебное gело», ГБОУ ВПО Красноярский госуяарственный меgицинский университет им. проф. В.Ф. Войно-Ясенецкого МЗ РФ.

Agрес: 660022, г. Красноярск, ул. Партизана Железняка, g. 1; meл.: 8 (391) 2280628; e-mail: Svetik55067@mail.ru.

\section{Authors}

Petrova Marina Mikhaylovna - Dr.Med.Sc, Professor, Head of Department of ambulance care State Educational Institution of High Professional Education Krasnoyarsk State Medical University named after Prof. V.F. Voino-Yasenetsky.

Address: 1, Partizana Zheleznyaka str., Krasnoyarsk, Russia, 660022; phone: 8 (391) 2280628; e-mail:stk99@yandex.ru.

Pronina Elena Aleksandrovna - Doctor of Philosophy, Associate Professor at the Department of ambulance care State Educational Institution of High Professional Education Krasnoyarsk State Medical University named after Prof. V.F. Voino-Yasenetsky.

Address: 1, Partizana Zheleznyaka str., Krasnoyarsk, Russia, 660022; phone: 8 (391) 2280628; e-mail:diinny@mail.ru.

Baron Irina Iosifovna - Doctor of Philosophy, Associate Professor at the Department of ambulance care State Educational Institution of High Professional Education Krasnoyarsk State Medical University named after Prof. V.F. Voino-Yasenetsky.

Address: 1, Partizana Zheleznyaka str., Krasnoyarsk, Russia, 660022; phone: 8 (913) 5387810;e-mail: irinabaron@mail.ru.

Pozdnyakova Aleksandra Aleksandrovna - Student of 204 groups of Faculty of Basic Medical EducationPediatrics State Educational Institution of High Professional Education Krasnoyarsk State Medical University named after Prof. V.F. Voino-Yasenetsky.

Address: 1, Partizana Zheleznyaka str., Krasnoyarsk, Russia, 660022; phone: 8 (391) 2280628; e-mail: alex.pozdnyackowa@yandex.ru.

Romanova Maria Viktorovna - Student of 204 groups of Faculty of Basic Medical EducationPediatrics State Educational Institution of High Professional Education Krasnoyarsk State Medical University named after Prof. V.F. Voino-Yasenetsky.

Address: 1, Partizana Zheleznyaka str., Krasnoyarsk, Russia, 660022; phone: 8 (391) 2280628; e-mail: Romil_16@mail.ru.

Yaganova Svetlana Sergeevna - Student of 202 group, Faculty of Basic Medical Education of General Medicine State Educational Institution of High Professional Education Krasnoyarsk State Medical University named after Prof. V.F. Voino-Yasenetsky.

Address: 1, Partizana Zheleznyaka str., Krasnoyarsk, Russia, 660022; phone: 8 (391) 2280628; e-mail: Svetik55067@mail.ru. 